\title{
Estimasi Nilai Ripitabilitas dan MPPA (Most Probable Producing Ability) Produksi Susu Sapi FH di Peternakan Noviciat Claretian Benlutu, Kabupaten Timor Tengah Selatan
}

\author{
Herminus Winarto Un ${ }^{\mathrm{a}}$, Veronika Y. Beyleto ${ }^{\mathrm{b}}$, Agustinus Agung Dethan ${ }^{\mathrm{c}}$ \\ ${ }^{a}$ Fakultas Pertanian, Universitas Timor, Kefamenanu, TTU - NTT, 85613, Indonesia. \\ ${ }^{b}$ Fakultas Pertanian, Universitas Timor, Kefamenanu, TTU - NTT, 85613, Indonesia. \\ ${ }^{c}$ Fakultas Pertanian, Universitas Timor, Kefamenanu, TTU - NTT, 85613, Indonesia.
}

\section{Article Info}

\section{Article history:}

Received 12 Mei 2015

Received in revised form 12 Juni 2015

Accepted 7 Agustus 2015

\section{Keywords:}

Ripitabilitas

Most Probable Producing Ability

MPPA

Sapi FH

\begin{abstract}
Abstrak
Penelitian ini bertujuan untuk mengetahui besarnya nilai ripitabilitas (angka pengulangan) dan MPPA (Most Probable Producing Ability) produksi susu perlaktasi sapi FH yang dihasilkan di peternakan Noviciat Claretian Benlutu, dilaksanakan di Peternakan Sapi Perah FH Novisiat Claretian Benlutu selama 1 bulan yakni 5 Januari sampai dengan 5 Februari 2015. Materi yang digunakan dalam penelitian ini adalah catatatan (recording) umur sapi betina pada waktu mengalami laktasi, lama laktasi pada setiap periode laktasi, frekuensi pemerahan per hari dan produksi susu per laktase sapi FH. Catatan tersebut merupakan catatan dari 13 ekor induk sapi FH dengan jumlah laktasi 5 kali. Metode yang digunakan adalah metode survei. Data yang diambil adalah data primer tentang gambaran umum peternakan sapi perah dan data sekunder yakni catatan produksi susu per laktasi. Nilai ripitabilitas yang diperoleh dalam penelitian ini diestimasi dengan metode korelasi intra kelas karena semua induk sapi FH yang datanya digunakan dalam penelitian ini memiliki catatan produksi susu sebanyak lima kali. Hasil penelitian menunjukkan nilai estimasi ripitabilitas produksi susu sapi FH di Peternakan Noviciat Claretian Benlutu adalah $0.54 \% \pm 0.27 \%$. Estimasi nilai MPPA tertinggi berdasarkan lebih dari dua catatan produksi dicapai oleh induk sapi Delia yakni 1937,42 liter dan terendah dimiliki oleh induk sapi Lusia 1806,21 liter dengan rata-rata MPPA produksi susu adalah 1869,68 liter \pm 47.48 liter Hal ini menunjukkan bahwa induk sapi FH di lokasi penelitian memiliki kemampuan yang bervariasi dalam menghasilkan air susu. @2016 dipubikasikan oleh JAS.
\end{abstract}

\section{Pendahuluan}

Susu merupakan produk peternakan yang bernilai gizi tinggi dan mempunyai peranan penting dalam upaya meningkatkan kesehatan dan kecerdasan masyarakat. Permintaan masyarakat akan pentingnya nilai gizi susu per kapita di Indonesia terus meningkat dari tahun ketahun. Sementara itu produksi susu nasional juga mengalami peningkatan, akan tetapi belum mampu mengimbangi permintaan akan kebutuhan susu yang semakin meningkat. Tujuan utama usaha ternak sapi perah adalah mendapatkan keuntungan dari hasil produksinya yang berupa susu.

Penampilan produksi seekor ternak sapi dalam menghasilkan susu, dipengaruhi oleh faktor genetik dan faktor lingkungan. Adanya perbedaan factor genetik dan faktor lingkungan menimbulkan keragaman produksi. Keragaman genetik pada suatu populasi merupakan suatu alasan pentingnya untuk dilakukan seleksi. Seleksi merupakan tindakan untuk memilih calon tetua jantan dan betina berdasarkan performans individu ternak yang bersangkutan maupun berdasarkan performans anak keturunannya. Keberhasilan seleksi dapat dicapai apabila ada informasi parameter genetik yakni ripitabilitas (angka pengulangan) selain heritabilitas (angka pewarisan) dan korelasi genetik. Seleksi dapat dilakukan berdasarkan potensi genetik namun potensi genetik tidak dapat dilihat namun hanya dapat diestimasi berdasarkan fenotipnya.

Menurut Hadiyanto (1994 ), sapi Friesh Holland (FH) adalah jenis sapi yang dapat menghasilkan air susu melebihi dari kebutuhan anaknya dan merupakan salasatu dari ternak perah yang mampu merubah makanan menjadi air susu yang sangat bermanfaat bagi anak-anaknya maupun bagi manusia.

Seleksi induk sapi FH dapat dilakukan dengan menghitung nilai MPPA (Most Probable Producing Ability) atau kemampuan berproduksi berdasarkan produksi susu induk tersebut. Menurut (Warwick et al. (1990), MPPA merupakan suatu taksiran yang mendekati kemampuan produksi secara riil dari seekor ternak betina yang dinyatakan sebagai simpangan terhadap rata-rata kelompok, pada MPPA pembilangnya menggunakan repitabilitas. MPPA berguna untuk menduga keunggulan seekor/kelompok individu untuk mengulang produksinya, individu dengan nilai MPPA produksi susu yang tingg diprediksi akan menghasilkan keturunan dengan produksi susu yang tinggi pula.

Seleksi induk dengan menggunakan MPPA hanya dilakukan untuk memilih induk unggul (Hardjosubroto, 1994). Lasley (1978) mengemukakan bahwa MPPA merupakan kemampuan berproduksi seekor ternak yang erat kaitannya dengan nilai ripitabilitas, rataan produksi, dan rataan produksi populasi.

Untuk menduga nilai MPPA dari suatu individu, diperlukan catatan produksi dan nilai ripitabilitas dari individu tersebut. Nilai MPPA produksi susu sapi FH dihitung dengan menggunakan informasi besarnya nilai ripitabilitas produks susu. Menurut Rice et al. (1957), ripitabilitas atau repeatability berasal dari kata repeat yang berarti pengulangan dan ability yang berarti kemampuan. Dengan demikian repitabilitas berarti kemampuan seekor individu atau kelompok ternak sapi perah untuk mengulangi produksi selama hidupnya. Atau merupakan sebuah ukuran kekuatan hubungan antara ukuran yang berulang-ulang suatu sifat dalam populasi. Sifat dapat di tentukan individu yang umurnya mempunyai catatan produksi lebih dari satu, misalnya produksi susu pada sapi perah. Selanjutnya Warwick et al. (1990) menyatakan setiap hasil pengamatan produks menggambarkan hasil kerja sama antara faktor genetik dan faktor lingkungan Apabila pengamatan dilakukan berulang kali maka hasil pengamatan pada lingkungan yang pertama akan berbeda dengan lingkungan ke dua dan lingkungan pada pengamatan ke dua tidak sama dengan lingkungan pada pengamatan berikutnya. Sejauh mana hubungan antara produksi pertama dengan produksi yang berikutnya pada individu tersebut inilah yang disebut angka pengulangan (Ripitabilitas)
Peternakan sapi perah milik Noviciat Claretian Benlutu merupakan salah satu tempat pemeliharaan dan pengembangan sapi perah $\mathrm{FH}$, namun selama ini pengembangannya tidak berdasarkan hasil seleksi ternak terutama potensi genetiknya. Tujuan penelitian ini adalah untuk mengetahui besarnya nilai ripitabilitas (angka pengulangan) dan MPPA produksi susu sapi FH yang dihasilkan di peternakan Noviciat Claretian Benlutu.

\section{Metode}

Penelitian ini telah dilaksanakan di Peternakan Sapi Perah FH Noviciat Claretian Benlutu, Kabupaten Timor Tengah Selatan selama satu bulan yakni 5 Januari sampai dengan 5 Februari 2015. Materi yang digunakan dalam penelitian ini adalah catatatan (recording) umur sapi betina pada waktu mengalami laktasi, lama laktasi pada setiap periode laktasi, frekuensi pemerahan per hari dan produksi susu perlaktase sapi FH. Catatan tersebut merupakan catatan dari 13 ekor induk sapi $\mathrm{FH}$ dengan jumlah laktasi 5 kali milik peternakan sapi perah Noviciat Claretian Benlutu.

Penelitian menggunakan metode survei. Data yang diambil adalah data primer tentang gambaran umum peternakan sapi perah dan data sekunder yakni catatan produksi susu per laktasi. Variabel penelitian ini adalah nilai ripitabilitas produksi susu dan nilai MPPA produksi susu.

Ripitabilitas produksi susu diestimasi dengan metode korelasi dalam kelas dan dihitung berdasarkan lebih dari dua catatan per individu menggunakan rumus sesuai petunjuk Warwick et al. (1990). Nilai MPPA atau kemampuan produksi dihitung sesuai petunjuk Hardjosubroto (1994)

\section{Hasil dan Pembahasan}

3.1 Keadaan Umum Lokasi Penelitian

Peternakan sapi FH milik biara Noviciat Claretian terletak di Desa Benlutu Kecamatan Batu Putih, Kabupaten TTS (Timor Tengah Selatan) Propinsi NTT (Nusa Tenggara Timor). Bangsa sapi yang di pelihara di lokasi penelitian adalah sapi perah FH (Friesh Holland) murni yang didatangkan dari Australia. System perkawinan adalah kawin alam dengan umur beranak pertama 2 tahun calving intervalnya 2 tahun. Lama penggunaan induk adalah 10 tahun dan pejantan 12 tahun. Ternak afkir di potong. Selama hidup induk sapi perah FH mengalami 5 kali laktasi dengan lama pemerahan 305-308 hari atau 10 bulan. Frekuensi pemerahan adalah 2-3 kali/hari secara manual. Pakan yang diberikan berupa lamtoro, turi dan rumput sedangkan konsentrat diberikan saat sapi sedang laktasi, pemberian air minum secara terus menerus.

Pembersihan kandang dilakukan 2 kali sehari yakni pagi hari dan sore hari, jumlah sapi yang ada di peternakan milik Noviciat Claretian Benlutu saat ini adalah 15 ekor induk dan 4 ekor pejantan yang merupakan keturunan dari sapisapi yang diambil datanya dalam penelitian ini.

\subsection{Estimasi Nilai Ripitabilitas Produksi Susu}

Ripitabilitas merupakan salah satu parameter genetic yang digunakan untuk sifat-sifat yang muncul beberapa kali dalam hidup seekor ternak seperti produksi susu. Ripitabilitas merupakan bagian dari ragam total suatu populasi yang disebabkan karena perbedaan-perbedaan individu yang bersifat permanen, sehingga ripitabilitas meliputi semua pengaruh genetic ditambah pengaruh lingkungan yang permanen. Nilai ripitabilitas yang diperoleh dalam penelitian ini diestimasi dengan metode korelasi intra kelas karena semua induk sapi $\mathrm{FH}$ yang datanya digunakan dalam penelitian ini memiliki catatan produksi susu sebanyak lima kali. Warwick et al (1990) dan Hardjosubroto (1994) menyatakan bahwa nilai ripitabilitas dapat diestimasi dengan metode korelasi intra kelas apabila setiap individu memiliki lebih dari dua catatan produksi. 
Nilai estimasi ripitabilitas yang diperoleh dalam penelitian ini adalah sebesar $0.54 \pm 0.27$ dan termasuk dalam kategori tinggi. Menurut Dalton (1980), estimasi ripitabilitas termasuk kategori tinggi apabila nilainya berkisar antara $30 \%-$ $100 \%$. Nilai ripitabilitas produksi susu yang tinggi menunjukkan bahwa kelompok induk yang diambil datanya memiliki kemampuan yang tinggi untuk mengulangi produksinya dalam menghasilkan anak dengan produksi susu yang relatif sama (Warwick et al, 1990).

Nilai estimasi ripitabilitas produksi susu sapi FH di Peternakan Noviciat Claretian Benlutu termasuk kategori tinggi dan sudah berada dalam kisaran normal. Hardjosubroto (1994) mengatakan bahwa nilai ripitabilitas atau angka pengulangan produksi susu adalah senilai $0,40-0,60$.

Ripitabilitas dipengaruhi oleh factor genetic yakni pengaruh gen aditif atau kombinasi dari gen dominan dan epistasis dan pengaruh lingkungan permanen. Keragaman genetik dan lingkungan rendah ripitabilitas berada dalam kategori tinggi dan sebaliknya apabila keragaman lingkungan temporer besar menyebabkan nilai ripitabilitas rendah (Pattie dan James, 1985).

Hasil estimasi nilai ripitabilitas produksi susu $\mathrm{FH}$ yang diperoleh dalam penelitian ini lebih tinggi dari hasil estimasi nilai ripitabilitas produksi susu sapi FH yang dilaporkan oleh Prahanisa, dkk (2011) yakni $0,15 \pm 0,05$. Hal ini disebabkan karena perbedaan populasi yang diestimasi nilai ripitabilitasnya. Nilai parameter genetik (ripitabilitas) suatu sifat tergantung pada populasi, jumlah data dan metode estimasi yang digunakan (Stansfield dan Erlod, 2007). Selanjutnya Warwick et al. (1990) menyatakan bahwa nilai parameter genetik suatu sifat dilokasi yang sama dapat menunjukkan perbedaan karena perbedaan genetik individu-individu yang diamati yang disebabkan oleh seleksi.

3.3 Estimasi Nilai MPPA (Most Probable Producing Ability)

Salah satu cara menduga kemampuan berproduksinya seekor sapi betina adalah dengan menghitung nilai MPPA (Most Probable Producing Ability). Informasi yang diperlukan untuk menghitung nilai most probable producing ability (MPPA) meliputi produksi susu per laktasi setiap individu, rata-rata produksi susu populasi, banyaknya laktasi setiap individu, dan nilai ripitabilitas produksi susu populasi.

Rata-rata produksi susu lactase pertama sampai laktasi kelima berturut-turut adalah: $2173,43 \pm 80,84 ; 1845,11 \pm 68,69 ; 1751,68 \pm 64,32 ; 1735,98 \pm 63,93$ dan $1842,17 \pm 46,15$ liter. Estimasi nilai MPPA produksi susu sapi FH yang diperoleh dalam penelitian ini berturut-turut dapat dilihat dalam Tabel 1.

Tabel 1. Estimasi nilai MPPA sapi FH (Liter)

\begin{tabular}{lc}
\hline Induk sapi FH & Nilai MPPA \\
\hline Delia & 1937,42 \\
Shinta & 1929,86 \\
Ida & 1922,78 \\
Klara & 1910,23 \\
Marta & 1907,40 \\
Weli & 1873,16 \\
Ratu & 1872,06 \\
Antonia & 1848,22 \\
Karolina & 1830,41 \\
Pepita & 1830,34 \\
Dede & 1829,19 \\
Ana & 1808,49 \\
Lusia & 1806,21 \\
\hline
\end{tabular}

Data Tabel 1. menunjukkan bahwa estimasi nilai MPPA (Most probable Producing Ability) tertinggi berdasarkan lebih dari dua catatan produksi dicapai oleh induk sapi Delia yakni 1937,42 liter dan terendah dimiliki oleh induk sapi Lusia 1806,21 liter dengan rata-rata MPPA produksi susu adalah 1869,68 liter \pm 47.48 liter. Hal ini menunjukkan bahwa induk sapi FH di lokasi penelitian memiliki kemampuan yang bervariasi dalam menghasilkan air susu.

Estimasi nilai MPPA dalam penelitian ini lebih rendah dari yang dilaporkan Prahanisa et al. (2011) yakni nilai MPPA tertinggi 4853.23 liter dan terendah 4368,44 liter. Hal ini diduga disebabkan karena perbedaan genetik dan lingkungan permanen yang menyebabkan perbedaan nilai ripitabilitas. Dalton (1980) menyatakan bahwa nilai MPPA yang berbeda disebabkan karena perbedaan nilai ripitabilitas.

\section{Simpulan}

a. Estimasi nilai ripitabilitas produksi susu sapi Friesh Holland di Peternakan Noviciat Claretian Benlutu, termasuk kategori tinggi yakni 0.54 \pm 0.27 .

b. Estimasi nilai MPPA sapi Friesh Holland di Peternakan Noviciat Claretian Benlutu tertinggi dimiliki oleh sapi Delia yakni 1937,42 liter dan terendah adalah sapi Lusia yakni 1806,21 liter dengan nilai rata-rata MPPA adalah $1869,68 \pm 47.48$ liter

\section{Pustaka}

Dalton D.C. 1980. An Introduction to Pratical Animal Breeding. Edisis Kedua. English Language Book Society. New York.

Hadiyanto. 1994. Susu Sapi Perah. Dairy Technology Improvement Project in Indonesia. Bandung

Hardjosubroto W. 1994. Aplikasi Pemuliabiakan Ternak di Lapangan. Gramedia Jakarta.
Lasley J. F. 1978. Genetic of Livestock Improvement. 3rdEd. Prentice Hall of India Private. New Delhi

Pattie W. A. dan J. W. James. 1985. Principles of Applied Animal Breeding. Departemen of Animal Production University of Queensland. Australia.

Prahanisa H, Sumadi dan Adiarto. 2011. Estimasi Potensi Genetik Sapi Perah FH di Taurus Dairy Farm Cicurug, Sukabumi. Buletin Peternakan Vol.35 (1):1-10. Fapet. UGM. Yogyakarta.

Rice, V.A., F.N. Andrews, E.J Warwick and J.E. Legates. 1957. Breeding and Improvement of Farm Animals. McGrow-Hill Book Company Inc. Kogakusha Company, Ltd. Tokyo

Stansfield, W. D dan S. L. Elrod., 2007. Schaum's Outlines Teori dan Soal-Soal Genetika, Edisi Keempat. Terjemahan Damaring Tyas W. dan A. Safitri. Penerbit Erlangga, Jakarta.

Warwick E. J. Maria A dan Wartomo H. 1990. Pemuliaan Ternak. Gadjah Mada University Press. Yokyakarta. 